\title{
COMPROMETIMENTO E ÉTICA PROFISSIONAL: UM ESTUDO DE SUAS RELAÇÕES JUNTOS AOS CONTABILISTAS
}

\author{
COMMITMENT AND PROFESSIONAL ETHICS: A STUDY \\ OF BOTH AMONGST ACCOUNTING PROFESSIONALS
}

\author{
ERIVAN BORGES \\ Professor Assistente do Departamento Ciências Contábeis \\ do Centro de Ciências Sociais Aplicadas \\ da Universidade Federal do Rio Grande do Norte - RN \\ E-mail: erivan@ufrnet.com.br
}

\author{
CARLOS MEDEIROS \\ Professor Adjunto do Departamento de Administração \\ do Programa de Pós-graduação em Administração \\ do Centro de Ciências Sociais Aplicadas \\ da Universidade Federal do Rio Grande do Norte - RN \\ E-mail: carlosalberto@digi.com.br
}

\section{RESUMO}

Neste trabalho, apresenta-se um estudo das relações do comprometimento com a ética profissional junto aos profissionais da área contábil, na tentativa de averiguar se o nível de introjeção dos valores éticos influencia o seu nível de comprometimento. $\mathrm{Na}$ etapa empírica, foram utilizados dois instrumentos de mensuração, sendo um relativo ao comprometimento organizacional de Medeiros (2003), adaptado para a profissão, com 28 (vinte e oito) indicadores e outro com 20 (vinte), construído a partir do teorizado por Lisboa et al. (1997), que foi inspirado no código de ética do contador gerencial do Institute of Management Accountants, como um conjunto de quatro preceitos mínimos: a competência, o sigilo, a integridade e a objetividade, que na visão dos autores, representam as bases mínimas exigidas num código de ética, analisados a partir das técnicas de análise fatorial, regressão linear e test "t". Constatou-se que o comprometimento é influenciado pelo nível de introjeção ética e que existe diferenciação no comprometimento por parte das duas categorias profissionais: técnicos e contadores. O resultado do estudo mostra que o profissional de nível superior tem seu comprometimento influenciado diretamente pelo nível de introjeção dos deveres éticos da profissão em quatro bases diferentes, e o técnico em contabilidade em duas. O estudo mostra, também, que a objetividade é o maior preditor do comprometimento, sendo esse mais bem evidenciado pelos aspectos instrumentais e normativos, possibilitando considerar que as relações de troca e de necessidade se apresentam como salientes diante da atuação ética dos contabilistas.

Palavras-chave: Ética; Ética Profissional; Códigos de Ética; Preceitos Éticos; Comprometimento.

\section{ABSTRACT}

This paper presents a study in commitment issues related to professional ethics amongst professionals in Accounting. It aims to verifying whether the introjections of ethical values influence commitment level. In the empirical phase of the research, two measurement instruments were used, one related to organizational commitment, Medeiros (2003) that was adapted to the profession, with 28 (twenty-eight) indicators and the other one with 20 (twenty). This was done considering Lisboa et al (1997) that was inspired on the ethics code of managerial accounting of the Institute of Management Accountants. The documents relate four minimal ethical precepts: competence, secrecy, integrity and objectiveness; all of which from the authors' point of view, represent the minimal basis required on an ethics code. They were analyzed.from the factorial analysis and the " $t$ " test and it was found out that the commitment issue is influenced by the level of ethical introjections and that there is a differentiation on commitment amongst technicians and accountants. Study results show that the professionals of higher education have their commitment level influenced directly by the introjections of the ethical duties of the profession in four different instances. As for the accounting technician, there are two instances. The study also indicates that objectiveness is the greatest predictor in commitment and this is better shown by normative and instrumental aspects. Therefore, it allows to inferring that relations based on exchange of needs is presented here as a key factor in the ethical performance of accountants.

Keywords: Ethics; Professional Ethics; Ethics Code; Ethical Precepts; Commitment. 


\section{INTRODUÇÃO}

O aumento da complexidade dos negócios, da velocidade das inovações tecnológicas e da informação, impõem ao mundo corporativo novas maneiras de realizar transações empresariais e profissionais. As crescentes disparidades e desigualdades obrigam os componentes da sociedade a rever o desenvolvimento num contexto geral, ou seja, econômico, político, social e profissional. Esse desenvolvimento desencadeia e catalisa a concorrência, tornando empresas e profissionais membros permanentes de uma robótica do meio. Agora, todos esses buscam novos meios, processos de gestão e atuação, investindo e reinventando, objetivando diferenciar-se competitivamente e tentando redimensionar a imagem do complexo que é a relação com as pessoas e a sociedade.

Nesse contexto, os indivíduos que exercem uma profissão aberta ao mercado devem possuir elementos capazes de colocá-lo numa posição diferenciada em relação aos seus pares. E isso se materializa na sua capacidade técnica, seu compromisso social e profissional, e com a sua postura ética, exigências latentes no mundo dos negócios. Esses últimos elementos, compromisso e postura ética, destacam-se pela peculiaridade existente na ação do profissional, conforme delimita Ashley et al. (2005).

Essas exigências, também, são preocupações existentes na carreira profissional em contabilidade, que no Brasil foi regulamentada através do Decreto-lei 9.295 de maio de 1946. Esse ato institucionalizador criou o Conselho Federal e os Conselhos Regionais de Contabilidade que representam os profissionais e têm o poder de regulamentar as normas e os atos da profissão. O mesmo decreto dividiu a profissão em duas categorias: técnicos e contadores, caracterizados pelo nível de formação acadêmica e por um conjunto de prerrogativas profissionais estabelecidas através da Resolução CFC nº. 560 de 1983.

Nesse sentido, é necessário que os contabilistas estejam preparados tecnicamente, e possuam um nível de comprometimento capaz de identificá-los como profissionais diferenciados e que não estejam abertos à participação ou coniventes com atos e ações reconhecidas pela sociedade como imorais ou ilícitas, o que só pode ser alcançado com a introjeção e conseqüente demonstração, através de suas ações, dos seus valores e deveres éticos pessoais e sociais.

Lisboa et al. (1997), tratando da ética profissional, apresentam um conjunto de elementos que devem estar inseridos nas ações dos profissionais em contabilidade, materializados no código da profissão, que envolve questões de obediência às regras da sociedade, ao servir com lealdade e diligência, e ao respeito próprio. Para os autores são quatro os preceitos mínimos a serem considerados no exercício profissional e num conseqüente manual de conduta: a) competência; b) sigilo; c) integridade e d) objetividade.

Esse conjunto de preceitos engloba a atuação do profissional que
[...] deve manter um comportamento adequado às exigências que lhe faz a sociedade. Lisboa et al. (1997, p. 61).

Enfatizam, dizendo que não basta ao profissional a preparação técnica, mas encontrar uma finalidade social superior nos serviços que executa, defendendo os princípios e valores éticos da profissão, de tal forma a produzir uma imagem verdadeira do que ela se constitui, Lisboa et al. (1997, p. 62).

No que tange à pesquisa do comprometimento, ela vem sendo largamente estudada no campo organizacional. Os estudos têm um referencial histórico caracterizado pela descoberta de um conjunto de componentes múltiplos que formam o que se delimita como "construto do comprometimento", Medeiros (2003).

Os componentes até agora estudados reportam-se aos vínculos mantidos pelo empregado com a organização $e$ são divididos em quatro: o Afetivo, que delimita o sentimento dos indivíduos de permanecerem numa organização porque eles querem; o Instrumental, que diz que indivíduos permanecem numa organização porque eles precisam; o Normativo, que aponta que indivíduos permanecem numa organização porque se sentem obrigados, e o Afiliativo, que estabelece que os indivíduos permanecem numa organização porque se sentem parte dela.

A descoberta desses componentes tem seu maior referencial nos trabalhos desenvolvidos pelos pesquisadores canadenses Meyer e Allen (1991), que como afirmam Mathieu e Zajac (1990), representam os maiores pesquisadores sobre o tema comprometimento na década de 90, e Medeiros et al. (1999), que identificaram, a partir da validação do instrumento de Meyer, Allen e Smith (1993), a existência de um novo componente latente no construto, denominando-o de Afiliativo, determinando que os empregados permanecem na organização porque se sentem parte dela.

Muitos estudos destacam a importância de serem efetuadas novas abordagens sobre o tema, enfatizando a necessidade de se explorar, em novas culturas e contextos, a confirmação dos aspetos conceituais até agora estudados, através da validação de instrumentos, bem como de tentar procurar novas dimensões para o construto comprometimento, além das já teorizadas e validadas, Medeiros e Enders (1998).

Outra abordagem envolvendo o tema comprometimento refere-se à pesquisa no campo das carreiras e profissões, que apesar do que afirma Bastos (1994), quando diz que o comprometimento com a profissão não chega a representar, sozinho, uma linha sistemática de estudo, vem crescendo em decorrência do elevado número de profissionais que surgem na sociedade, como apontam Morrow e Wirth (1989).

Sendo um construto em construção e partindo do entendimento de Meyer, Allen e Smith e outros autores de que comprometimento não é um construto unidimensional, é possível inferir cientificamente e abordar o tema comprome- 
timento em contextos diferenciados, utilizando-se, inclusive, os focos organizacionais das profissões e carreiras, como forma de validar as pesquisas até agora apresentadas.

Esta pesquisa buscou estabelecer e conhecer as relações existentes entre ética profissional e comprometimento. Tentou entender, como elemento principal, as relações existentes entre a introjeção de deveres éticos e o comprometimen- to no exercício da profissão pelos contabilistas; de forma que os resultados, mesmo em níveis mínimos, possam colaborar com as entidades reguladoras da classe, na delimitação de deveres e obrigações profissionais que promovam o crescimento individual dos vários stakeholders envolvidos com a profissão, e também da própria organização.

\section{O COMPROMETIMENTO E SUAS ABORDAGENS}

O estudo do comprometimento vem sendo trabalhado em muitas áreas, inclusive nos aspectos profissionais. Ele vai muito além de uma postura de lealdade, mais que isso, envolve uma busca constante pelo bem comum, seja numa organização ou numa profissão (MOWDAY, STEERS, e PORTER, 1979; MOWDAY, PORTER e STEERS, 1982).

A ligação do indivíduo com uma organização materializa-se pela introspecção por parte daquele das crenças e valores desta, de forma tal que se crie um sentimento de afeição, fazendo-o desejar permanecer ou continuar a exercer suas funções, Bastos e Costa (2001).

A predominância do enfoque afetivo destacou-se nos trabalhos desenvolvidos pela equipe liderada por Lyman Porter (MOWDAY, STEERS e PORTER, 1979; MOWDAY, PORTER e STEERS, 1982). O comprometimento, para esses autores, supera o sentimento de lealdade passiva, pois envolve, também, um relacionamento ativo que busca o bem-estar da organização.

O segundo enfoque que, igualmente, preponderou nos estudos do comprometimento foi o Instrumental, derivado dos estudos de Becker (1960). O autor conceitua comprometimento instrumental como uma tendência do indivíduo em se engajar em "linhas consistentes de atividade". Para Becker, o indivíduo permanece na empresa devido aos custos e benefícios associados a sua saída, que seriam as trocas laterais, assim passa a se engajar em linhas consistentes de atividade para se manter no emprego.

O enfoque normativo é apresentado nos trabalhos de Wiener (1982), encontrando-se referências sobre ele nos trabalhos de Kanter (apud MOWDAY, PORTER e STEERS, 1982), publicado em 1968. Para o autor, o comprometimento é definido como:

a totalidade das pressões normativas internaliza-

das para agir num caminho que encontre os objetivos e interesses organizacionais. Wiener (1982 p.421).

Acrescenta, ainda, que o ponto central dessa definição, em aceitar os valores e objetivos organizacionais, configura-se como uma forma de controle sobre as ações dos indivíduos, denominando-o de normativo-instrumental. Para ele, os indivíduos que são comprometidos exibem comportamentos diferenciados porque aceitam e acreditam que é certo fazê-lo. O autor diz, ainda, que a visão normativa está centrada no conjunto de controles normativos existentes nas organizações, como normas e regulamentos.
O enfoque afiliativo é apresentado nos trabalhos exploratórios de Medeiros et al. (1999) e confirmatório, Medeiros (2003). Os estudos que delimitam tal enfoque são recentes e sua validação ocorreu apenas em três pesquisas, todas a partir dos trabalhos desenvolvidos por Medeiros. O destaque e a conceitualização proposta pelo autor encontra base nos trabalhos desenvolvidos por Kelman (1958) e Becker (1992) que afirmam que o vínculo psicológico do indivíduo com uma organização se baseia num sentimento de identificação e afiliação. Gouldner (1960), também, reforça o conceito proposto por Medeiros, delimitando que das duas dimensões propostas para o comprometimento uma se refere a um sentimento de fazer parte da organização.

Todos os enfoques apresentados envolvem, apenas, medidas unidimensionais do comprometimento, limitadas, já que outros autores identificaram a existência de dimensões diferentes no comportamento e no vínculo dos indivíduos com as organizações.

Historicamente, vários foram os enfoques dados aos estudos das multidimensões do comprometimento. Kelman (1958) foi o primeiro a estabelecer o comprometimento com mais de um componente, delimitando-o em três bases independentes, chamando de: a) Compliance, que explicita submissão, ou envolvimento instrumental, motivado por recompensas externas; b) Identification, identificação, ou envolvimento baseado num desejo de afiliação e c) Internalization, internalização, ou envolvimento causado pela congruência entre os valores individuais da organização.

Allen e Meyer (1990) desenvolveram estudos relativos ao comprometimento considerando a existência de múltiplas dimensões que são internacionalmente conhecidas e aceitas.

Essa visão exploratória das várias dimensões do comprometimento vem sendo aplicada e estudada em larga escala, o que mostra que o tema ainda encontra espaço para validação e pesquisa, haja vista que o próprio estudo do comprometimento, enquanto conceito subjetivo é campo árido e longe de unificação consensual. Os próprios autores já apontavam que o estudo do comprometimento com base no modelo de três componentes não encerra o assunto. Ressaltam em seus estudos que

não é claro que os três componentes estabelecidos aqui são os únicos componentes relevantes do comprometimento ou que cada um represente um constructo unitário. Meyer e Allen (1991, p. 82). 
Continuam, em trabalho posterior, afirmando serem necessários mais estudos que envolvam o tema (Meyer e Allen, 1997).

Medeiros et al., em pesquisa realizada em 1999, validaram o modelo de três componentes proposto por Meyer, Allen e Smith (1993) e encontraram um quarto, que passaram a denominá-lo de afiliativo, caso em que o indivíduo permanece numa organização porque ele se sente parte dela. Esses autores, também, afirmaram ser necessária a validação dos instrumentos de mensuração do construto em outras culturas e contextos, o que foi feito neste trabaIho junto aos profissionais que atuam na área contábil.

\subsection{Comprometimento com a Profissão}

O enfoque das pesquisas do comprometimento com as profissões não chega a representar uma linha consistente de pesquisa, como afirma Bastos (1994). Apesar dessa informação, esse enfoque vem alcançando níveis acentuados de importância, de forma que Blau (2003) e outros autores chegam a afirmar que a direção dos estudos atuais saem do foco na organização e tendem à profissão e à carreira.

Um problema comum às pesquisas, nesse campo, refere-se à terminologia aplicada aos estudos: ocupação, profissão ou carreira? Bastos (1994) faz um levantamento das principais pesquisas na área e apresenta os principais conceitos para os três termos na visão de alguns pesquisadores. O autor, ainda, aponta que os termos são usados como sinônimos, sem a diferenciação necessária à abrangência de cada um. Esse pensamento é consubstanciado por Meyer et al. (2003).

As três abordagens apresentadas, também, são focos de tentativas da delimitação de um construto, às vezes utilizando-se a junção dos termos ocupação, carreira e profissão.

Neste trabalho, utilizou-se a terminologia comprometimento com a profissão, destacando a contabilidade como profissão restritiva àqueles que possuem as prerrogativas legais exigidas, consoante ao apontado por Kast e Rosenzweig apud Bastos (1994), que afirmam que as profissões possuem especificidades como:

a) a existência de um corpo sistemático de conhecimento que requer lento processo de formação $e$ treinamento envolvendo tanto aspectos intelectuais como atividades práticas;

b) um grau de autoridade conferida pelos clientes em função do conhecimento técnico especializado; c) um amplo conhecimento social como base para o exercício da autoridade;

d) um código de ética que regula entre os pares e entre o profissional e seus clientes;

e) uma cultura profissional que é mantida pelas organizações.

Essas características restringem a atuação como profissional apenas àqueles indivíduos que se inserem no conjunto de prerrogativas exigidas do grupo. E esse grupo representa uma classe profissional, com status social diferenciado de uma ou outra ocupação, pois possui elementos restritivos que vão desde a exigência de uma habilidade e formação individual à obediência a um código de ética, não sendo, portanto, de amplitude genérica como as ocupações e as carreiras.

\subsection{Os Antecedentes do Comprometimento}

O estudo do comprometimento engloba as pesquisas relacionadas a elementos que o precedem, estão a ele atrelados ou mesmo são conseqüências da sua existência. São o que a literatura chama de antecedentes, correlatos e conseqüentes do comprometimento. Esses três elementos são estudados como variáveis que influenciam ou são influenciadas pelo comprometimento em diversos estudos, inclusive no campo das profissões.

Relativamente à profissão e às carreiras, Steers (1977) afirma que quanto maior for o nível de educação do indivíduo menor será seu comprometimento com a organização e maior será com a sua carreira ou com a sua profissão. Os estudos de Steers e outros pesquisadores não são consensuais na indicação das variáveis antecedentes. A Confirmação dáse em pesquisas conjuntas do próprio autor, que concordou com Mowday et al. (1982), que os antecedentes do comprometimento estão classificados em quatro categorias: características pessoais, características do trabalho, experiências do trabalho e características estruturais.

Mathieu e Zajac (1990) apontam, como antecedentes do comprometimento, as características pessoais, as relações grupo versus líder, as características organizacionais e os estados de percepção da função (role states).

O estudo de Medeiros (2003) apresenta a abordagem das características organizacionais como antecedentes ao comprometimento dos indivíduos.

\section{A ÉTICA PROFISSIONAL E OS CÓDIGOS DE ÉTICA}

O objeto da Ética é o estudo do comportamento humano e o seu objetivo é estabelecer níveis de convivência aceitáveis entre os indivíduos de uma sociedade, Lisboa et al. (1997).

Aristóteles (2002) diz que o convívio social é o principal indicador da adesão de um indivíduo à idéia de um conjunto. $O$ autor preconiza o objetivo geral da ética quando afir- ma que "Na ordem natural, o Estado antepõe-se à família e a cada indivíduo, visto que o todo deve, obrigatoriamente, ser posto antes da parte.", Aristóteles (2002, p. 14). Afirma, ainda, que o indivíduo que não consegue conviver em sociedade pode ser comparado a uma ave de rapina, pois não é capaz de se submeter a nenhuma obediência.

Morgan (1996, p. 153) diz que os empregados 
[...] trazem para o local de trabalho aspirações e visões daquilo que o seu futuro deve ser, fornecendo as bases para interesses de carreira que podem ser independentes do trabalho que está sendo desempenhado.

Parece divergente o pensamento dos dois autores, mas quando se fala em ética e comportamento individual e social o que é dito por Morgan não supera a proposição de Aristóteles, e o que é proposto por Aristóteles não invalida o pensamento de Morgan. O comportamento ético alia a filosofia dos dois autores, pois as aspirações individuais apontadas por um, quando se fala em ética, na verdade, estão dentro das aspirações coletivas referenciadas pelo outro.

Nesse sentido, agir eticamente é saber conviver em sociedade, aceitando o conjunto como precedente à parte. Essa aceitação não significa perda de valores individuais, mas antes, crescimento coletivo. E esse crescimento, obtido pela ação ética consciente, reveste-se como indicador e diferencial indispensáveis não só na atuação das pessoas, mas de empresas e profissionais.

Hoje, mais do que nunca, a atitude dos profissionais em relação às questões éticas pode ser a diferença entre o seu sucesso e o seu fracasso. Basta um deslize, uma escorregadela, e pronto. A imagem do profissional ganha, no mercado, a mancha vermelha da desconfiança. Jacomino (2000, p. 28).

As atitudes delineadas pelo autor referem-se ao conjunto de preceitos éticos que um profissional tem de possuir e aplicar na sua atuação. Na visão de Lisboa et al. (1997), isso engloba o nível de conhecimento a respeito de assuntos técnicos da profissão, a integridade no agir, o respeito aos pares e à própria classe, o grau de reserva com as informações em decorrência do seu exercício profissional, e com o grau de objetividade que mantém nas informações que presta aos seus contratantes e colaboradores.

Na visão de Sá (2001), uma profissão supera a utilidade individual para quem a exerce e destaca-se por suas características sociais e morais. O autor apresenta como fatores esclarecedores desse pensamento, o proposto por Cuvillier:

1. É pela profissão que o indivíduo se destaca e se realiza plenamente, provando sua capacidade, habilidade, sabedoria e inteligência, comprovando sua personalidade para vencer obstáculos.

2. Através do exercício profissional, consegue o homem elevar seu nível moral.

3. É na profissão que o homem pode ser útil à sua comunidade e nela se eleva e destaca, na prática dessa solidariedade orgânica. Sá, (2001, p. 129).

A ética profissional pode, então, ser conceituada como o conjunto de condutas técnicas e sociais exigidas por uma determinada classe aos membros que a ela são ligados. A obediência ao código de conduta identifica o profissional como ético e ele, por seu comportamento, alcança o reco- nhecimento dos demais membros da própria classe e da sociedade em geral.

A ética reporta-se, necessariamente, a toda prática humana, seja ela profissional ou não. A rigor, existe, ou deveria existir, uma ética aplicada a cada atividade profissional. A ética profissional nasce da progressiva especialização das atividades humanas, como afirma Aguiar (2003).

Essa especialização pode ser entendida como uma conquista própria do indivíduo que buscou, nessa área de conhecimento, uma parte daquilo que é exposto pelos filósofos gregos como felicidade. A conquista denota satisfação pessoal e conseqüente prêmio pela dedicação. Sua conduta ética é, na verdade, a aceitação primeira dos valores do grupo, que, como afirma Aguiar (2003, p. 69), devem estar antes de tudo na consciência do indivíduo e não obliterar seu livre arbítrio.

\subsection{Composição e Preceitos de um Código de Ética}

Os códigos de ética representam o conjunto de elementos que caracterizam o comportamento das pessoas dentro de um grupo social. Dentre esses elementos, destacam-se os deveres legais normativos e positivos e as regras de boa conduta no trato com as pessoas.

Analisando o conteúdo de 17 códigos de empresas originadas no Brasil, Arruda (2002), com base num modelo de análise e comparação de códigos de conduta proposto pelos pesquisadores holandeses Tulder e Kolk (2001), apresenta os principais enfoques dados pelas organizações sobre a preocupação ética. A autora elenca 27 itens para análise, adaptado do modelo de Tulder e Kolk, que enfatiza critérios relativos a questões éticas com as pessoas, relativos ao foco, à mensuração e de compliance, Arruda (2002, p. 24 e 25).

A análise destaca que os principais componentes se reportam à ética como comportamento correto com as pessoas, à obediência a requisitos legais, aos interesses do consumidor e aos interesses comunitários.

Nash (2001) apresenta, como resultado de uma pesquisa na qual analisou mais de 200 códigos de ética, um conjunto de valores que movem o idealismo dos indivíduos, destacando como tais: a honestidade, a integridade, a família, a realização, a confiabilidade, a justiça, a lealdade, a credibilidade, o respeito pelos outros e o respeito próprio. Para a autora, a ética nos negócios é mais bem definida como integridade nos negócios. Para tanto, caracteriza a integridade como sendo a condição que exige que você aja como diz Nash (2001, p. 34). Para ela, são 4 os valores básicos de um código de conduta: a honestidade, a confiabilidade, a justiça e o pragmatismo.

Lisboa et al. (1997) apresentam um conjunto de preceitos mínimos que devem constar de um código de ética. A conclusão tem como base a análise do código de ética do contador gerencial do Institute of Management Accountants. Os autores destacam 4 elementos que sintetizam o objetivo principal de um código de ética: a COMPETÊNCIA, o SIGILO, a INTEGRIDADE e a OBJETIVIDADE. 


\begin{tabular}{|l|l|l|}
\hline Lisboa (1997) & \multicolumn{1}{|c|}{ Nash (2001) } & \multicolumn{1}{c|}{ Arruda (2002) } \\
Competência & Honestidade & Ética com as pessoas \\
\hline Sigilo & Confiabilidade & Requisitos legais \\
\hline Integridade & Justiça & Interesses do consumidor \\
\hline Objetividade & Pragmatismo & Interesses comunitários \\
\hline
\end{tabular}

Quadro 1 - Comparação dos estudos de Arruda, Nash e Lisboa et al.

A competência, para os autores, ressalta o nível de preparação técnico-profissional e a aderência às normas e preceitos legais, a capacidade de preparar relatórios claros e completos, com recomendações apropriadas para análise, Lisboa et al. (1997, p. 69). O sigilo demonstra o grau de reserva que o profissional tem com as informações que Ihe são confiadas por clientes, colaboradores e demais stakeholders.

A integridade demonstra a conduta do profissional diante dos seus pares, sua classe, clientes e concorrentes. Nesse ponto, os autores desmembram a integridade em fatores que vão desde o seu comportamento social até as suas atitudes individuais. Evitar conflitos de interesses, esclarecendo seu compromisso e independência profissional aos clientes; abster-se de receber prêmios ou presentes, a fim de não prejudicar a sua independência; não tomar decisões isoladas que possam colocar em risco a consecução dos objetivos da empresa ou do seu contratante, bem como criar uma política de esclarecimento e comunicação tempestiva das suas opiniões e julgamentos junto a administradores e clientes, Lisboa et al. (1997, p. 70).

A objetividade, ressaltam Lisboa et al. (1997), demonstra o grau de clareza que o profissional tem no trato e na transmissão das informações que repassa aos clientes e contratantes, bem como a evidenciação dos dados relevantes que possam influenciar as decisões por parte deles. Essa objetividade não se restringe, apenas, ao conteúdo da informação, mas antes à capacidade do profissional em facilitar o entendimento de assuntos técnicos aos diversos usuários.

O Quadro $1 \mathbf{0}$ apresenta uma comparação dos estudos apontados.

Os elementos apontados por Arruda e Nash são frutos dos estudos em organizações, não se destacando sua inteira aplicação às carreiras profissionais. Por tal motivo, a abordagem adotada neste trabalho segue o modelo proposto por Lisboa et al. (1997), que serve de base ao instrumento elaborado para medição do nível de introjeção dos valores éticos.

\section{METODOLOGIA}

Nessa seção, são apresentados os aspectos metodológicos do trabalho, considerando tipologia, população, amostra instrumento e procedimentos de coleta e análise de dados.

\subsection{Tipo de Pesquisa}

Esta pesquisa é tipificada como exploratóriodescritiva(o), procurando validar os construtos comprometimento e introjeção ética. Exploratória porque objetivou proporcionar aos pesquisadores um maior envolvimento com o problema, e o conseqüente aprimoramento de idéias e descobertas sobre o assunto. Descritiva porque apresenta relações entre variáveis já abordadas cientificamente, conforme aponta Oliveira et al. (2003).

\subsection{População, Amostra e Procedimentos de Coleta}

A pesquisa foi aplicada numa amostra de 187 indivíduos componentes de uma população total de 2.415 profissionais em contabilidade, atuantes na cidade de Natal/RN, selecionada a partir do cadastro geral do CRC/RN, em julho de 2005.

A amostra tentou contemplar o maior número de elementos possíveis da população, não sendo determinada $a$ priori. Seu tamanho contemplou o resultado final da aplicação dos instrumentos, que foram enviados via Internet a todos os componentes da população que tinham e-mail cadastrado no CRC/RN, em intervalos regulares de até sete dias. Além desse procedimento, foram realizadas reuniões presenciais na sede do Conselho e visitas promovidas aos maiores escritórios de contabilidade da Cidade. O período de coleta de dados foi de 20 de julho a 25 de agosto de 2005.

Do total de entrevistados, $25,13 \%$ são do sexo feminino e $74,87 \%$ do sexo masculino. A idade média dos entrevistados é de 36,8 anos, variando de 21 a 69 anos. O tempo médio de atuação profissional chega a 10,8 anos e o número de horas diárias dedicadas à profissão é, em média, de 8 horas por dia.

\subsection{Instrumento de Coleta de Dados}

$O$ instrumento utilizado foi elaborado numa escala tipo Likert de seis pontos, composto por 48 itens, que variam de "discordo totalmente" a "concordo totalmente". Sua composição engloba 28 questões de comprometimento do instrumento utilizado por Medeiros (2003) e 20 elaboradas a partir dos elementos apontados por Lisboa et al. (1997), 
como preceitos mínimos que devem constar de um código de ética, salientando a competência, o sigilo, a integridade e a objetividade. A construção desse questionário deu-se pela falta de modelos nas pesquisas sobre o tema que comportassem os preceitos citados por Lisboa et al. (1997).

\subsection{Análise de Dados}

Para a identificação das dimensões latentes do comprometimento e de introjeção ética, esta pesquisa utilizou a técnica de análise fatorial. Kerlinger (1980) afirma que a análise fatorial é um método analítico para determinar o número e a natureza de variáveis subjacentes a um grande número de variáveis e medidas.

Para identificar as relações de causa e efeito entre o nível de introjeção ética profissional e o comprometimento, a pesquisa utilizou a técnica de análise de regressão múltipla. A técnica de análise de regressão múltipla permite identificar um conjunto de variáveis independentes que atuam na explicação de uma variável dependente.

\section{ANÁLISE E DISCUSSÃO DOS RESULTADOS}

A análise e discussão dos resultados são apresentadas, considerando a identificação das dimensões encontradas através da análise fatorial exploratória e as relações de causa e efeito entre os construtos comprometimento e introjeção ética, considerando o referencial teórico utilizado.

\subsection{Dimensões Latentes com os Indicadores de Introjeção Ética}

$A$ análise fatorial dos indicadores constantes do instrumento elaborado na pesquisa identificou um total de 7 fatores iniciais. Por ter sua construção fundamentada teoricamente em Lisboa et al. (1997), a pesquisa buscava dimensionar 4 fatores: Competência, Integridade, Sigilo e Objetividade.

A rotação inicial apresentou o total de 7 fatores não totalmente definidos, mas com dimensões latentes identificáveis teoricamente. Como alguns dos itens fugiam da dimensão original prevista, foi feita a exclusão a fim de que os primeiros fatores se ajustassem à teoria apresentada a respeito da introjeção ética. Essa exclusão foi feita com o objetivo de demonstrar, com base no referencial teórico existente, os indicadores que melhor representavam as dimensões previstas para medição do nível de introjeção ética. Assim, foram retirados os indicadores que prejudicavam a interpretação do fator, pois o valor do Alpha era aumentado com a retirada do indicador. Os itens excluídos foram comp2, comp3, sig2, sig5, int1, int5, obj1 e obj2.

Inicialmente, foi feita a exclusão de um indicador em cada dimensão, na tentativa de identificar em cada um 4 variáveis para sua composição. Como não se ajustavam de forma consistente, retirou-se, então, mais um indicador de cada dimensão, possibilitando a rotação dos 4 fatores teóricos esperados. Percebeu-se, no final, a ligação consistente de três indicadores em cada, medindo-se o nível de confiabilidade de cada um e da rotação total.

A conclusão quanto à consistência de cada fator representa o que Hair et al. (2005) definem como responsabilidade do pesquisador em assegurar que os fatores formados são conceitualmente válidos. A fundamentação parte do proposto por Lisboa et al. (1997) quando delimita que um código de ética deve conter pelo menos quatro elementos mínimos que ele conceitua como sendo: a competência, o sigilo, a integridade e a objetividade.

Hair et al. (2005) estabelecem que uma das maneiras de fixar o número mínimo de fatores que devem ser extraídos da análise é a observação do autovalor. Esse critério engloba apenas aqueles que têm esse valor maior que um, sendo esse o critério adotado neste trabalho.

Após a exclusão de todos os itens referenciados, a análise reuniu 4 fatores com autovalor maior que um, todos conceitualmente identificados.

A Tabela 10 apresenta o conjunto de fatores identificados na análise para o construto introjeção ética, que são associados, em seguida, ao referencial apresentado na seção 3 .

O fator formado pelos indicadores: a) int3 - Eu sempre procuro manter relações de cordialidade e honestidade com meus clientes e colegas de profissão; b) int4 - Eu procuro sempre ser cordial e honesto nas minhas abordagens diárias a clientes e colegas de profissão e c) int2 - O profissional deve sempre manter uma relação de cordialidade e honestidade com seus clientes e colegas de profissão, independentemente dos interesses deles, confirma o exposto por Lisboa et al. (1997), sendo, então, denominado

Tabela 1 Variação explicada e autovalor dos componentes da introjeção ética

\begin{tabular}{c|c|c|c} 
Componentes & Autovalor & Variação explicada & $\begin{array}{c}\text { Variação explicada } \\
\text { acumulada }\end{array}$ \\
\hline 1 & 2,95 & 24,55 & 24,55 \\
\hline 2 & 1,96 & 16,34 & 40,89 \\
\hline 3 & 1,52 & 12,69 & 53,58 \\
\hline 4 & 1,20 & 10,02 & 63,60
\end{tabular}

Fonte: Dados primários coletados pelos autores 
de Integridade, que segundo o autor representa a conduta do profissional diante dos seus pares, sua classe, clientes e concorrentes.

Silva e Speroni (1998) dizem que uma das características da ética é um maior relacionamento do indivíduo com seus clientes e com outros profissionais, levando em conta valores como a dignidade humana, a auto-realização e a sociabilidade. O ser honesto e cordial com seus pares e contratantes, na verdade, expõe o lado mais íntegro do profissional.

O segundo fator é formado pelos itens: a) sig2 - Eu guardo total sigilo sobre o que sei em razão do meu exercício profissional; b) sig1 - O profissional deve guardar reserva total sobre o que souber em razão do seu exercício profissional e c) sig4 - Eu guardo sigilo total sobre acontecimentos ocorridos no Conselho da classe dos quais sei em razão do meu exercício profissional. A composição desse fator compreende o que Lisboa et al. (1997) chamam de Sigilo.

O terceiro fator resultante é composto pelos indicadores: a) comp5 - Procuro cumprir toda a legislação fiscal, independentemente da opção tributária do meu cliente; b) comp4 - Eu cumpro toda a legislação fiscal e contábil independente dos interesses dos meus clientes e c) comp1 - Eu cumpro integralmente as normas e os deveres da profissão, refletem o conceituado por Lisboa et al. (1997) como Competência, que ressalta o nível de preparação técnico-profissional e a aderência às normas e preceitos legais, Lisboa et al. (1997, p. 69).

O último fator rotacionado, na análise, reporta-se à objetividade, que segundo Lisboa et al. (1997) demonstra o grau de clareza e objetividade que o profissional tem no trato e na transmissão das informações que repassa aos clientes e contratantes, bem como a evidenciação dos dados relevantes que possam influenciar as decisões tomadas por eles. O fator foi formado pelos indicadores: a) obj5 - Procuro ser totalmente objetivo nas informações que presto aos meus clientes, sejam elas favoráveis ou desfavoráveis a eles; b) obj4 - Eu procuro me inteirar de todas as circunstancias dos assuntos sobre os quais sou consultado para ser objetivo nas minhas respostas e c) obj3 - Eu sempre procuro ser objetivo e facilitar o entendimento dos meus clientes a respeito de assuntos técnicos da profissão.

\subsection{Dimensões Latentes com os Indicadores do Comprometimento}

As rotações fatoriais aplicadas sobre os indicadores referentes ao comprometimento com a profissão, possibilitaram a formação de 6 fatores iniciais com 3 indicadores cada um, coadunando-se com o trabalho de Medeiros (2003, p. 79).

A Tabela 20 apresenta os componentes extraídos e a variação explicada e acumulada de cada fator para o construto comprometimento, que são associados, em seguida, ao referencial apresentado na seção 2 .

O primeiro fator formado foi o Afetivo. O fator é composto pelos indicadores: a) afe4 - Eu acredito nos valores e objetivos desta profissão; b) afe $\mathbf{3}$ - Eu me identifico com a filosofia desta profissão; c) afe1 - Desde que me juntei a esta profissão, meus valores pessoais e os da profissão têm se tornado mais parecidos, convalida o achado por Medeiros em pesquisa conduzida em hotéis e shoppings.

Mowday, Porter e Steers, apud Medeiros (2003) conceituam o fator como uma forte crença e a aceitação dos objetivos e valores de uma organização, destacada através dos indicadores assemelhados na dimensão.

O segundo fator é formado pelos indicadores: a) inst2 - Na situação atual, exercer a minha profissão é na realidade uma necessidade tanto quanto um desejo; b) inst3 - Para conseguir ser recompensado nesta profissão é necessário expressar a atitude certa; c) inst1 - Procuro não transgredir as regras da minha profissão, pois, assim, sempre manterei minhas prerrogativas profissionais. O conjunto de indicadores denotam o comprometimento Instrumental, ou linhas consistentes de atividade, que delimitam que um indivíduo é comprometido com sua profissão pelo conjunto de interações e trocas entre ele e a organização. $A$ atuação do profissional segue um caminho ou referência padrão, de forma que atenda aos interesses múltiplos.

Hrebiniak e Alutto (1972) chamam a atenção para a proporção estrutural construída em decorrência do conjunto de benefícios adquiridos e investimentos realizados pelo indivíduo no seu trabalho.

O terceiro fator é formado pelos indicadores a) norp4 Acredito que não seria certo deixar minha profissão porque tenho uma obrigação moral em permanecer exercendo-a; b) norp1 - Eu não deixaria minha profissão agora porque

Tabela 2 | Variação explicada e autovalor dos componentes do Comprometimento

\begin{tabular}{c|c|c|c} 
Componentes & Eigenvalor & Variação Explicada & $\begin{array}{c}\text { Variação Explicada } \\
\text { Acumulada }\end{array}$ \\
\hline 1 & 4,35 & 24,19 & 24,19 \\
\hline 2 & 2,62 & 14,59 & 38,78 \\
\hline 3 & 1,84 & 10,24 & 49,01 \\
\hline 4 & 1,58 & 8,37 & 57,39 \\
\hline 5 & 1,34 & 7,45 & 64,83 \\
\hline 6 & 1,12 & 6,24 & 71,08
\end{tabular}

Fonte: Dados primários coletados pelo autor 
eu tenho uma obrigação moral em permanecer exercendoa; c) norp3 - Eu me sentiria culpado se deixasse minha profissão agora.

A composição do fator engloba o que é definido por Wiener (1982, p.421) como "a totalidade das pressões normativas internalizadas para agir num caminho que encontre os objetivos e interesses organizacionais". Para ele, os indivíduos que são comprometidos em termos normativos exibem comportamentos diferenciados porque aceitam e acreditam que é correto e certo fazê-lo. Complementa, ainda, que a visão normativa está centrada no conjunto de controles normativos existentes nas organizações, como as normas e os regulamentos.

O Código de Ética do Profissional Contabilista - CEPC e o conjunto de resoluções editadas pelos conselhos caracterizam-se como "normas e regulamentos", reforçando o defendido por Wiener (1982). As características do comprometimento normativo são apresentadas por Fishbein (1967) e Wiener (1982).

O quarto fator formado reporta-se ao comprometimento instrumental "recompensas e oportunidades" identificado pela ligação dos indicadores ao que O'Reilly e Chatman (1986) chamam de Submissão. O fator é formado pelos indicadores: a) recom3 - Minha visão pessoal sobre esta profissão é diferente daquela que eu expresso publicamente; b) recom2 - A menos que eu seja recompensado de alguma maneira, eu não vejo razões para despender esforços extras em benefício desta profissão; c) recom1 - Se eu já não tivesse dado tanto de mim nesta profissão, eu poderia considerar exercer outra.

No campo das profissões é possível depreender que esse comprometimento se refere ao acúmulo patrimonial e ao respeito adquirido ao longo de sua vida profissional, pois sua atuação dependerá do retorno que ele venha a ter pelo exercício de suas prerrogativas. Também denota o aspecto de obediência como elemento protetor, uma vez que, estando dentro de uma sociedade profissional, o indivíduo está sujeito ao conjunto de regras e normas impostas ao grupo. E ele passa a cumpri-las de forma singular procurando evitar punições ou limitações ao exercício de sua profissão.

Isso é corroborado pelo que afirma Becker (1992) quando diz que o indivíduo tem um comprometimento instrumental delineado pelas recompensas e oportunidades para, além da intenção de obter um retorno, preservar-se para não ser punido.

O quinto fator retrata os indicadores: a) nord2 - Eu tenho obrigação em desempenhar bem minha profissão; b) nord3 - O bom profissional deve se esforçar para que a seus contratantes tenham os melhores resultados possíveis; c) nord1 - Todo profissional deve buscar atingir os objetivos dos seus contratantes. Destaca o comprometimento normativo e o sentimento de obrigação do indivíduo decorrente do seu desempenho.

A característica saliente do fator reporta-se ao que é exposto por Wiener (1982) como sendo o total das pressões internalizadas pelos indivíduos para agir num caminho que possa levá-lo ao encontro dos objetivos da organização.
O sexto e último fator delineado na pesquisa reportase ao que Medeiros (2003) concluiu como o comprometimento relacionado ao sentimento de afiliação do indivíduo como seu contratante. Essa afiliação é tratada, na literatura, como um forte desejo de fazer parte de uma organização. O fator é composto pelos indicadores: a) afiz - Sou reconhecido por todos nesta profissão como um membro da classe; b) afi3 - Sinto que meus colegas me consideram como membro da classe profissional; c) afi1 - Nesta profissão, eu sinto que faço parte da classe profissional.

$\mathrm{O}$ autor destaca que, com base no que preconizou Kelmam (1958) e Becker (1992), esse sentimento é diferenciado do que outros autores conceituam como comprometimento afetivo. Enquanto aquele leva o indivíduo a se sentir parte, como elemento construto de estrutura, esse outro denota a introspecção real e total por parte do indivíduo dos valores da organização.

O comprometimento afiliativo possibilita uma relação de entender os objetivos de uma organização ou profissão, que é foco deste trabalho, sem necessariamente ter seus valores pessoais sobrepostos pelos da profissão ou organização. O comprometimento afetivo, do contrário, é identificado pela introjeção dos valores de uma profissão ou organização, já que eles são congruentes com os do indivíduo, Kelmam apud Medeiros(2003).

Assim, é possível depreender que o comprometimento afiliativo denota um vínculo psicológico racional, sem a confusão de valores pessoais e profissionais ou organizacionais. O indivíduo sente-se parte do processo, mas preserva, pelo menos parcialmente, seus valores e sentimentos pessoais.

\subsection{Relações de Causa e Efeito entre o Nível de Introjeção Ética Profissional e o Comprometimento}

A regressão linear elaborada no estudo possibilitou responder ao proposto como problema central de pesquisa, e a algumas das questões suscitadas, estabelecendo uma relação de causa e efeito entre o nível de introjeção ética dos profissionais e o seu comprometimento. $O$ conjunto de fatores formados pela rotação fatorial proporcionou a identificação dos elementos tratados como antecedentes e preditores do comprometimento.

A tentativa de se estabelecerem relações das variáveis éticas como preditoras do comprometimento afetivo não revelou nenhuma relação entre as variáveis. As demais relações apresentaram apenas um fator como influente no nível de comprometimento dos contabilistas.

A relação das variáveis éticas como antecedentes do comprometimento normativo (sentimento de obrigação em permanecer exercendo a profissão) revelou apenas a objetividade como elemento antecedente. $O$ que se apresenta, nessa relação, talvez seja explicado pelas próprias características da profissão. Sendo uma atividade em que, necessariamente, não é preciso estar ligado a uma empresa como empregado, mas ao contrário, de cunho preponderantemente liberal, os indivíduos mantêm rela- 
ções de troca sem subordinação, o que certamente afasta a idéia de obrigação imediata, senão pela reciprocidade entre contratante e contratado.

A relação das variáveis éticas como antecedentes do comprometimento instrumental (linhas consistentes de atividades) revelou apenas o fator objetividade como antecedente ao comprometimento instrumental, denotando que quanto maior for o grau de clareza e objetividade dos profissionais da área contábil maior será seu vínculo e conseqüente comprometimento com a profissão na busca de resultados e compensações.

Dentre as características profissionais exigidas pelo mercado aparecem aquelas ligadas à capacidade intelectual do indivíduo e também da sua mesma capacidade de traduzi-la ao entendimento de contratantes e da própria sociedade. Sendo objetivo, o profissional busca garantir a manutenção da confiança depositada por seu contratante, ser identificado como o elemento que é capaz e facilitador de conhecimento, como também um retorno material considerável por esse conjunto de atitudes.

Outro ponto a ser observado que explica a relação é o investimento feito pelo profissional na sua qualificação diante de uma possível mudança de atuação. Melhor será que o mesmo invista nessa qualificação, demonstrada pela sua capacidade de sintetização lógica, diante da descontinuidade do exercício profissional.

A relação variáveis éticas como antecedentes do comprometimento instrumental (recompensas e oportunidades) revelou apenas o sigilo como influente negativamente no comprometimento instrumental relativo à falta de recompensas e oportunidades. Na profissão contábil, o elemento ético é normatizado através de uma resolução de alcance nacional, a Resolução 803/96, o chamado Código de Ética da Profissão Contábil (CEPC), que traz no seu conjunto uma série de deveres e obrigações que devem ser prontamente obedecidas pelos contabilistas. Além do código em si, existe um conjunto de normas, as Normas Brasileiras de Contabilidade, que se referem aos aspectos de execução dos trabalhos, bem como à maneira de atuação dos profissionais.

Também é possível inferir, a partir da relação apresentada, que os profissionais da contabilidade atendem a essa determinação ética sem qualquer interesse conseqüente por tal comportamento. Há um convencimento interior, reforçando o que Aguiar (2003) caracteriza como senti- mento que deve estar antes de tudo na consciência, sem modificar ou interferir no livre arbítrio do indivíduo. O indivíduo, nesse caso, guarda sigilo porque entende isso como necessário, não esperando qualquer vantagem imediata por esse curso de ação escolhido.

A relação variáveis éticas como antecedentes do comprometimento normativo (sentimento de obrigação exercer a profissão pelo desempenho) revelou apenas o fator integridade como influente ao comprometimento normativo. Essa relação denota que o profissional que, na sua atuação, mantém um comportamento cordial e honesto com seus clientes e contratantes, também possui um elevado nível de comprometimento baseado na obrigação de exercer sua profissão por seu próprio desempenho, introjetando isso como parte daquilo que ele acha certo fazer para alcançar os melhores resultados possíveis para a profissão, na mesma proporção do que imagina para ele mesmo, evidenciando a cultura da profissão como a sua própria.

Deve-se levar, ainda, em consideração a característica normativa da profissão no que tange à obediência. Reveste-se, portanto, em dois pontos básicos, o obedecer para cumprir uma norma regulamentar, e o obedecer por aceitar aquilo como parte do que é aceito como verdadeiro.

A relação variáveis éticas como antecedentes do comprometimento afiliativo revelou apenas o fator competência como influente no comprometimento afiliativo. A base afiliativa do comprometimento é caracterizada pela aceitação do indivíduo dos valores de um conjunto na tentativa de ser reconhecido como parte dele, Kelman (1958).

O que se configura pela relação causal apresentada é o afastamento dessa afirmação, conseqüência talvez da posse, por parte do indivíduo, de um conhecimento elevado e que naturalmente o torna parte do grupo sem a sua aceitação do conjunto de regras para ser reconhecido como parte do grupo. Sua competência lhe dá essa condição, independentemente de suas ações dentro do grupo.

O resultado corrobora de igual modo o que delimita Steers (1997), quando afirma que quanto maior o nível educacional do indivíduo, nesse caso de preparação e competência, menor será seu comprometimento com uma organização e maior será seu comprometimento com sua carreira profissional. Esse último ponto é visto como a possibilidade de ação individual do profissional em se estabelecer sem a necessidade de estar ligado ao grupo.

\section{CONSIDERAÇÕES FINAIS}

O presente estudo atende ao proposto na literatura do comprometimento que enfatiza a necessidade de se observar o tema em novas culturas e contextos, o que foi feito adaptando-se múltiplos componentes do comprometimento organizacional para o comprometimento com a profissão. De igual modo, colabora, de forma exploratória, com a pesquisa sobre os preceitos éticos assimilados pelos profissionais em contabilidade na sua atuação.
Sobre o comprometimento, os resultados demonstram o que é consensual na literatura sobre a composição do construto, apresentado esse de forma multidimensional. No aspecto ético, percebeu-se que a introjeção dos preceitos apontados por Lisboa et al. (1997) são válidos e observáveis, sem apresentar diferenças consideráveis de fator a fator. Essa constatação pode ser conseqüência do aspecto normativo presente no código de ética profissional, que 
influencia o comportamento desses profissionais diante da possibilidade de sofrer sanções éticas e disciplinares, que vão de multas à suspensão do exercício profissional.

A pesquisa evidenciou que o nível de introjeção de valores e deveres éticos por parte dos profissionais em contabilidade influencia seu nível de comprometimento, o que ficou confirmado através do processo de regressão quando foram utilizados os elementos éticos como antecedentes ao comprometimento. Essa influência apresentou-se em bases unidimensionais, sem alcançar o conjunto de 4 preditores previstos em cada relação.

Percebeu-se que, apesar da influência diagnosticada, essa é retratada em pequenos níveis, destacando-se a objetividade como maior preditor do comprometimento, esse mais bem evidenciado pelos aspectos instrumentais e normativos, possibilitando considerar que as relações de troca e de necessidade se apresentam como proeminentes diante da atuação ética dos contabilistas.

Talvez o resultado apresentado no trabalho seja conseqüência da característica intrínseca maior do que representa um código de ética, já que ele, como elemento regulador, é de obediência obrigatória para todos os profissionais e, por isso, apresentem-se os comprometimentos instrumental e normativo como salientes, representando, assim, uma limitação ao estudo.

Essa constatação abre espaço para novas pesquisas nessa linha, de forma que outros contextos profissionais sejam analisados a fim de se confirmar o que ficou exposto no trabalho. Estas pesquisas podem envolver temáticas relacionadas às imagens pessoais dos componentes éticos diante da globalização e abertura de mercado. Também pode considerar se o conjunto de preceitos propostos pelos códigos de éticas das profissões liberais atendem aos objetivos gerais de cada uma, englobando interesses individuais e coletivos. Pode, ainda, contemplar a ética profissional e seus preceitos diante da revolução tecnológica, entre outros pontos.

Por fim, é certo afirmar que o presente estudo não encerra a pesquisa sobre a relação ética $x$ comprometimento, mas colabora à medida que atende ao fomentado em trabalhos anteriores quando valida construtos multidimensionais do comprometimento, propõe um elemento mensurador do nível de introjeção ética profissional e abre espaço para novas pesquisas sobre os temas abordados.

\section{Referências Bibliográficas}

ALLEN, N. J.; MEYER, J. P.. The measurement and antecedents of affective, continuance and normative commitment to the organization. Journal of Occupational Psychology. N. 63, 1-18, 1990.

AGUIAR, Emerson Barros de. Ética: Instrumento de Paz e justiça. 2. ed.. Natal: Tessitura, 2003.

ARISTÓTELES. POLÍTICA. Coleção a Obra prima de cada autor. São Paulo: Martin Claret, 2002.

ARRUDA, Maria Cecília Coutinho de. Código de Ética: Um instrumento que adiciona valor. São Paulo: Negócio Editora, 2002.

ASHLEY, Patrícia Almeida et al.. Ética e responsabilidade social nos negócios. 2 ed. São Paulo: Saraiva, 2005.

BASTOS, A. V. B.. Comprometimento organizacional: a estrutura dos vínculos do trabalhador com a organização, a carreira e o sindicato. UnB. Tese de Doutorado. 1994.

; COSTA, F. M.. Múltiplos comprometimentos no trabalho: articulando diferentes estratégias de pesquisa. In: Revista rPOT - Psicologia: Organizações e Trabalho. Santa Catarina: Programa de Pós Graduação em Psicologia da Universidade Federal de Santa Catarina, v.1, n. 1, janeiro/junho de 2001.

BECKER, H. S.. Notes on the concept of commitment. The American Journal of Sociology, n. 66, p. 32-40, 1960.

244, 1992.

, T. E. Foci and bases of commitment: are they distinctions worth making? Academy of Management Journal, n. 35(1), p. 232-

BLAU, G.. Testing for a four-dimensional structure of occupational commitment. Journal of Occupational and Organizacional Pshycology, v.76, p.469-488, 2003

GIL, Antonio Carlos. Métodos e técnicas de pesquisa social. 5. èd. São Paulo: Atlas, 1999.

GOULDNER, H. P.. Dimensions of organizational commitment. Administrative Science Quaterly. N. 4, p. 468-490, 1960.

HAIR, J. F.; ANDERSON, R. E.; TATHAM, R. L.; BLACK, W.C.. Multivariate data analysis. 5a. New Jersey: Prentice Hall, 2005.

HREBINIAK, L. G.; ALLUTO, J. A.. Personal and role-related factors in the development of organizational commitment. Administrative Science Quaterly, n.17, p. 555-573, 1972.

INSTITUTE OF MANAGEMENT ACCOUNTANTS. Standards of ethical conduct for management accountants. Management Accounting. Montvale, N.J., p. 24, Aug. 1994.

Statemeents on accounting: objectives of management accounting. New York, Statement n. 1B, June 17, 1982.

JACOMINO, Darlen. Você é um profissional ético? Revista Você S/A, ed. 25, ano 3, p. 28-36, São Paulo: jul., 2000.

KELMAN, H. C.. Compliance, identification, and internalization: three processes of attitude change. Journal of Conflict Resolution, n. 2, p. 5160, 1958.

KERLINGER, F. N.. Metodologia da pesquisa em ciências sociais. São Paulo: EDUSP, 1980. 
LISBOA, Lázaro Plácido et al.. Ética Geral e Profissional e Contabilidade. São Paulo: Atlas, 1997.

MATHIEU, J. E.; ZAJAC, D. M.. A review and meta-analysis of the antecedents, correlates, and consequences of organizational commitment. Psychologicol Bulletin, n.108(2), p. 171-194, 1990.

MEDEIROS, Carlos Albert Freire. Comprometimento organizacional: um estudo de suas relações com características organizacionais e desempenho nas empresas hoteleiras. 2003. Tese de doutorado. São Paulo: FEA/USP, SP.

; ENDERS, W. T.. Validação do modelo de conceitualização de três componentes do comprometimento organizacional (Meyer e Allen, 1991). Revista de Administração Contemporânea, n. 2(3), p. 67-87, 1999.

; SALES, I; OLIVEIRA; D.; MONTEIRO, T.C.. Três (ou Quatro?) componentes do comprometimento $\longrightarrow$ organizacional. In: ENANPAD 99, Foz do Iguaçu. Anais... do 23 Encontro da Anpad - Organizações - CD-ROM, 1999.

MEYER, J. P.; ALLEN, N. J.. A three-component conceptualization of organizational commitment. Human Resource Management Review. N.1, p. 61-89, 1991.

Commitment in the workplace: theory, research and application. Thousand Oaks: Sage Publications, 1997.

; SMITH, C. A.. Commitment to organizations and occupations: extension and test of a three-component $\longrightarrow$ conceptualization. Journal of Applied Psychology, N. 78(4), p. 538-551, 1993.

MOWDAY, R. T.; PORTER, L. W.; STEERS, R. M.. Employee-Organization linkages - the psychology of commitment, absenteism and turnover. New York: Academic Press, 1982.

$\overrightarrow{224-247,1979 \text {. }}$

; STEERS, R. M.; PORTER, L. W.. The measurement of organizational commitment. Journal of Vocational Behavior. N. 14, p.

MORGAN, Gareth. Imagens da organização. Tradução de Cecília Wiltaker Bergamini, Roberto Coda: São Paulo: Atlas, 1996.

MORROW, P. C.; WIRTH, R. E.. Work commitment among salaried profissionals. Journal Of Vocational Psychology, n. 34, p. 40-56, 1989.

NASH, Laura L.. Ética nas empresas: guia prático para solucões de problemas éticos nas empresas. São Paulo: Makron Books, 2001 - Tradução de Kátia Aparecida Roque, revisão de Peter Nadas.

OLIVEIRA, Antonio Benedito Silva, et al.. Métodos e Técnicas de Pesquisa em Contabilidade. São Paulo: Saraiva, 2003.

O'REILLY III, C.; CHATMAN, J.. Organizational commitment and psychological attachment: the effects of compliance, identification, and internalization on prosocial behavior. Journal of Applied Psychological, n. 71(3), p. 492-99, 1986.

SÁ, A Lopes de. Ética profissional. 4a. ed.. São Paulo: Atlas, 2001.

SILVA, Tania Moura da; SPERONI, Valdemar. Os princípios éticos e a ética profissional. Revista Brasileira de Contabilidade, Brasília: CFC, ano 27, n. 113, p. 77-79, set./out. 1998.

STEERS, R. M.. Antecedents and outcomes or organizational commitment. Administrative Science Quarterly, 22, 46-56, 1977.

TULDER, Rob Van; KOLK, Ans. Multinationality and corporate Ethics: Codes of conduct in the Sporting goods industry. Journal of international business studies, 32, 2 (2 nd quarte 2001), p. 267-83

WIENER, Y.. Commitment in organizations: a normative view. Academy of Management Review, 7, 418-428, 1982.

\section{NOTA - Endereço dos autores}

Universidade Federal do Rio Grande do Norte

Caixa Postal 1524 - Campus Universitário Lagoa Nova

Natal - RN

$59072-970$ 